\title{
Socioeconomic Status and Other Factors Associated with Childhood Obesity
}

\author{
Amy S. Williams, MD, MSPH, Bin Ge, MD, MA, Greg Petroski, PhD, \\ Robin L. Kruse, PhD, Jane A. McElroy, PhD, and Richelle J. Koopman, MD, MS
}

Background: Childhood obesity in the United States is a critical public health issue. Although multiple child and parental factors are associated with childhood obesity, few models evaluate how socioeconomic status influences these risk factors. We aimed to create a model to examine how socioeconomic status modifies risk factors for child obesity.

Methods: We conducted a secondary data analysis of the Early Childhood Longitudinal Birth Cohort. Using logistic regression, we modeled childhood obesity status from known parental and child risk factors for childhood obesity and tested interactions with socioeconomic status.

Results: Compared with healthy-weight children, socioeconomic status, race, birth weight, parental smoking, and not eating dinner as a family were associated with kindergarten-aged children being overweight or obese. Parental smoking increased the odds of a child being overweight or obese by $40 \%$, and eating dinner as a family reduced the odds of a child being overweight or obese by $4 \%$. In addition, black or Hispanic children had a $60 \%$ increased odds of being overweight or obese when compared with their white counterparts. Native American children had almost double the odds of being overweight or obese compared with white children. Socioeconomic status did not modify any of these associations.

Conclusion: Parental smoking, birth weight, and not eating dinner as a family were two modifiable factors associated with overweight and obesity in kindergarten-age children, regardless of socioeconomic status. Changing these life-style factors could reduce the child's risk for obesity. ( $\mathrm{J}$ Am Board Fam Med 2018;31:514-521.)

Keywords: Pediatric Obesity, Primary Health Care, Public Health, Risk Factors, Socioeconomic Status

Childhood obesity is a critical public health issue, with one-third of all children and adolescents in the United States being either overweight or obese. ${ }^{1}$ Children who are overweight in kindergarten are 4 times more likely than healthy-weight children to be obese at age fourteen. ${ }^{2}$ Despite advances in obesity research, insufficient evidence exists about

This article was externally peer reviewed.

Submitted 3 July 2017; revised 8 December 2017; accepted 31 December 2017.

From Department of Family and Community Medicine (ASW, RLK, JAM, RJK) and Biostatistics and Research Design Unit, University of Missouri, Columbia, MO (BG, GP).

Funding: This project was internally funded by the Family and Community Medicine Department at the University of Missouri.

Conflict of interest: none declared.

Corresponding author: Amy S. Williams, MD, MSPH, Curtis W. and Ann H. Long Department of Family and Community Medicine, University of Missouri, 7 Hospital Drive, MA 306, Columbia, MO 65201 (E-mail: williamsamy@health. missouri.edu). how children develop obesogenic behaviors such as inactivity and poor nutritional preferences, especially in families of low socioeconomic status (SES). Recent studies suggest that children begin to develop health behaviors and attitudes as young as 5 years of age. ${ }^{3}$ Children as young as 4 or 5 years old may begin internalizing their parents' physical activity and dietary habits. A previous study shows that $71 \%$ of childhood obesity is explained by the influence of family factors on young children. ${ }^{4}$ This suggests that early childhood may provide the best window of opportunity for modifying environmental risk factors for childhood obesity.

The etiology of childhood obesity seems to be multifactorial. Child behavioral risk factors known to increase obesity risk include decreased physical activity rates ${ }^{5}$, increased time playing video games and watching television ${ }^{6}$, and being put to bed with a bottle. ${ }^{7}$ Some studies also show a strong association between birth weight and childhood obesity. ${ }^{8}$ 
Multiple studies document parental risk factors for their children's overweight status, including maternal obesity $^{8,9}$, lower educational attainment ${ }^{10}$, African American race ${ }^{11}$, lower physical activity rates ${ }^{12}$, poor nutrition knowledge ${ }^{12}$, food insecurity ${ }^{13}$, smoking ${ }^{8}$, rules about food consumption and eating at regular times ${ }^{14}$, and perceived neighborhood safety. ${ }^{14}$ The increased childhood obesity associated with these risk factors results in poor health outcomes in these children that persist as they become adults through the development of chronic diseases such as diabetes, hypertension, and coronary heart disease. ${ }^{15}$

Low family SES is associated with increased childhood obesity rates. Despite recent modest improvements in obesity rates among US low-income, preschool-aged children ${ }^{16}$, obesity rates continue to be higher among low-income children. ${ }^{17}$ However, this trend is not consistent in all races and at all SES levels. ${ }^{18}$ Some attribute the increased rate of obesity in minorities to their greater poverty rates. ${ }^{19}$ However, studies show that black children with higher SES do not exhibit the trend of lower obesity prevalence as do higher SES white children. ${ }^{18,20,21}$ In this study, we used a large national database to evaluate whether SES modifies risk factors for childhood obesity, including race. With this knowledge at hand, health care providers who care for children who are racial minorities can better address their pediatric patients' obesity by understanding the relationship between race, modifiable risk factors, SES, and childhood obesity.

Many modifiable risk factors for childhood obesity are related to SES, including neighborhood safety, smoking, drinking soda, and watching television. ${ }^{8}$ Demographic risk factors associated with increased childhood weight, such as race and birth weight, also vary with SES. Indeed, some have assumed that these risk factors are SES indicators rather than risk factors for childhood overweight status that are independent of SES. ${ }^{22}$ SES is importantly associated with health, including childhood obesity, but it is difficult to alter. Preventive health researchers and providers would benefit from a model that evaluates whether SES modifies the influence of these risk factors on early childhood weight. With such a model, they could design population-level and individual-level interventions that target modifiable risk factors for childhood obesity. Therefore, this study sought to test SES as a modifying risk factor for other demographic and be- havioral obesity risk factors associated with childhood obesity.

\section{Methods \\ Sample}

The Early Childhood Longitudinal Birth Cohort (ECLS-B) is a nationally representative sample of 14,000 children born in the United States in 2001. The subjects, from diverse socioeconomic and racial backgrounds, were followed during the formative years of birth through kindergarten entry. Parents were surveyed at their child's birth, at 9 months, 24 months, and 4 to 5 years of age. Surveys focused on child health, development, care, and education. In this study, we analyzed data from kindergarten entry (ages 4 to 5 years), which included 7,022 children. The ECLS-B employed a multistage, stratified, and clustered design for data collection. ${ }^{23}$ Data were collected at every round by trained assessors who visited the child and parents in their homes. At the visits, assessors measured height and weight, which were used to calculate body mass index (BMI). Children's BMI is classified by standard percentiles; those with a BMI greater than $85 \%$ were classified as overweight or obese, according to Centers for Disease Control and Prevention recommendations. ${ }^{24}$ The database also includes birth weight from US birth certificate data.

The ECLS-B oversamples children who are twins, Chinese and other Asian and Pacific Islanders, American Indians and Alaska Natives, and those born with low or very low birth weight. ${ }^{23}$ Researchers used weighted analysis to offset oversampling. The University of Missouri Health Sciences Institutional Review Board approved this project.

\section{Measures}

Our study's major outcome measure is the child's weight status (overweight or obese, $\geq 85$ th percentile vs healthy weight, $<85$ th percentile, based on age and gender), as measured during the ECLS-B kindergarten-entry visit. Assessors determined food security based on the survey at the same visit. The survey options were food secure, food insecure without hunger, and food insecure with hunger. Assessors also surveyed parents regarding parental household status at kindergarten entry, and we consolidated the categories into (1) 2-parent household 
or (2) other household status, including single-parent household. Assessors recorded the child's sex at birth as well as birth weight (in grams). We evaluated 6 categories of race ascertained at birth: white, black, Hispanic, Asian, Native American, and other. At 9 months, assessors asked parents if the child was routinely put to bed with a bottle (yes or no). Assessors determined the remainder of the behavioral variables at kindergarten entry. The parent survey included whether they had rules about which foods the child could eat (yes or no), if they had rules about what the child could watch on television (yes or no), how many hours of television the child watched each weekday (continuous variable up to 24 hours), how much soda their child consumed in the past 7 days $(0 / \mathrm{wk}, 1-3 / \mathrm{wk}, 4-6 /$ wk, $1 / \mathrm{d}, 2 / \mathrm{d}, 3 / \mathrm{d}, 4 / \mathrm{d}$ ), how many days per week the family eats at a regular time (0 to 7), how safe the parent felt the neighborhood was (very safe, fairly safe, fairly unsafe, very unsafe), and how many days in the past week the parent had exercised for 30 minutes or more (0 to 7). We considered but ultimately excluded the following variables from the model due to too much missing data: participation in free or reduced lunch at school, breastfeeding versus bottle feeding, child's habit of snacking after school, and amount of the child's aerobic exercise.

Household SES is a measure of a family's relative social position. The SES measure is based on 5 equally weighted, standardized components: family income, father's/guardian's educational attainment, mother's/guardian's educational attainment, father's/ guardian's prestige of occupation, and mother's/ guardian's prestige of occupation. This is a composite variable included in the ECLS database, with the fifth quintile being the highest. Parental education was coded with 9 categories (grades 0 to 11 , grade 12 without diploma or equivalent, high school diploma or equivalent, vocational/technical after high school, some college, Bachelor's degree, graduate or professional school but no degree, Master's degree, doctorate or professional degree after bachelor's degree) with the highest level of education in the household recorded and included birth parents, adoptive parents, step parents, and foster parents. Occupation was classified according to the Standard Occupation Classification Manual $^{25}$ and collapsed into 23 codes and the alternative codes of retired/unemployed and "uncodable." Each parent's occupation was scored using the average of the 1989 General Social Survey prestige scores for the 1980 census occupational category codes that correspond to the Early Childhood Longitudinal Study, Kindergarten Class (ECLS-K) occupation code. These prestige scores ranged from 77.5 for physicians/dentists/veterinarians to 29.6 for handlers/equipment cleaners/helpers/laborers. Household income was not relative to household size but rather was comprised of 18 categories that increased by intervals of $\$ 5,000$ starting at less than $\$ 5,000$ and increasing to greater than $\$ 200,000$. Rather than use income markers such as poverty level, we choose SES because it includes parental education and occupation in addition to household income. Thus, it is a more robust variable that may more fully describe then children's home environment. Other researchers have employed the SES composite variable to evaluate children's weight. ${ }^{26}$

\section{Statistical Analysis}

Simple logistic regression was used to assess the association between overweight status and each individual risk factor. Risk factors with $P<.2$ in the simple analyses were candidates for inclusion in a multivariable model. Logistic regression with stepwise variable selection was used to identify our main-effects risk model. A significance level of .05 was used as the variable entry and retention criteria in the stepwise process. Odds ratios (ORs) and 95\% CIs were calculated. The final phase of the regression analysis was to include 2-way interaction terms involving the selected main effects and SES. Only significant variables were included in the main effects model to test SES interaction term. Statistically significant interactions would suggest that the actual effects of a risk factor are influenced by SES. SAS 9.4 (SAS institute Inc., Cary, NC) was used for all analyses. SAS SURVEY procedures were used to accommodate the complex survey sample design. We conducted the analysis in 2015 and reviewed it in 2016 and 2017.

\section{Results}

Of the 7022 children in our analysis, $49.06 \%$ were female. The majority of children were white (53.80\%), followed by Hispanic (25.12\%), black (13.88\%), other races (3.94\%), Asian (2.62\%), and Native American (0.65\%). Most of the children $(68.96 \%)$ resided in 2-parent households, with both their biological mother and father. Overall, 36.31\% 
Table 1. Univariable Analyses of Factors Associated with Child Obesity in the Early Childhood Longitudinal Birth Cohort Data

\begin{tabular}{|c|c|c|c|c|}
\hline Risk Factors & $\mathrm{n}$ & Population \% & $\begin{array}{l}\% \text { Overweight or Obese } \\
(95 \% \mathrm{CI})\end{array}$ & Odds Ratio (95\% CI) \\
\hline \multicolumn{5}{|l|}{ Categorical variables } \\
\hline \multicolumn{5}{|l|}{ Socioeconomic status $(P<\mathbf{. 0 0 0 1})$} \\
\hline Quintile 1 (lowest) & 1263 & 19.91 & $44.94(40.47-49.41)$ & REF \\
\hline Quintile 2 & 1265 & 19.88 & $37.24(33.57-40.90)$ & $0.73(0.57-0.92)$ \\
\hline Quintile 3 & 1288 & 19.96 & $36.43(32.23-40.63)$ & $0.70(0.55-0.90)$ \\
\hline Quintile 4 & 1332 & 20.20 & $35.41(31.92-38.91)$ & $0.67(0.53-0.86)$ \\
\hline Quintile 5 (highest) & 1622 & 20.06 & $27.09(24.26-29.91)$ & $0.46(0.37-0.56)$ \\
\hline \multicolumn{5}{|l|}{ Food security $(P=.043)$} \\
\hline Food secure & 6034 & 89.71 & $35.45(33.82-37.07)$ & $0.61(0.38-0.98)$ \\
\hline Food insecure without hunger & 547 & 8.03 & $40.98(34.96-47.00)$ & $0.77(0.68-1.27)$ \\
\hline Food insecure with hunger & 171 & 2.26 & $47.39(35.47-59.30)$ & REF \\
\hline \multicolumn{5}{|l|}{$\begin{array}{l}\text { Parents who reside in household } \\
\qquad(\boldsymbol{P}=\mathbf{. 0 0 7 8})\end{array}$} \\
\hline $\begin{array}{l}\text { Biological mother and biological } \\
\text { father }\end{array}$ & 4705 & 68.96 & $34.61(32.73-36.49)$ & $0.80(0.68-0.94)$ \\
\hline Other household composition & 2065 & 31.04 & $39.75(36.53-42.97)$ & REF \\
\hline \multicolumn{5}{|l|}{ Race/ethnicity $(P<\mathbf{. 0 0 0 1})$} \\
\hline White & 2767 & 53.80 & $31.35(29.03-33.66)$ & REF \\
\hline Black & 1056 & 13.88 & $40.32(35.62-45.02)$ & $1.48(1.18-1.86)$ \\
\hline Hispanic & 1359 & 25.12 & $43.47(39.76-47.18)$ & $1.68(1.39-2.04)$ \\
\hline Asian & 765 & 2.62 & $28.69(22.82-34.57)$ & $0.88(0.67-1.16)$ \\
\hline $\begin{array}{l}\text { Native Hawaiian, Pacific Islander, } \\
\text { Alaska, or American Indian }\end{array}$ & 251 & 0.65 & $48.44(36.96-59.92)$ & $2.06(1.28-3.30)$ \\
\hline $\begin{array}{l}\text { Other race (includes more than } \\
\text { one race) }\end{array}$ & 560 & 3.94 & $43.39(36.77-50.00)$ & $1.70(1.26-2.24)$ \\
\hline \multicolumn{5}{|l|}{ Child's sex $(P=.28)$} \\
\hline Female & 3348 & 49.06 & $37.12(35.13-39.10)$ & $1.08(0.94-1.25)$ \\
\hline Male & 3422 & 50.94 & $35.26(32.63-37.89)$ & REF \\
\hline \multicolumn{5}{|l|}{$\begin{array}{l}\text { Child was put to bed with bottle } \\
\qquad(\boldsymbol{P}=\mathbf{. 0 1 4})\end{array}$} \\
\hline Yes & 2089 & 29.69 & $39.48(36.12-42.84)$ & $1.22(1.04-1.43)$ \\
\hline No & 4675 & 70.31 & $34.80(33.03-36.57)$ & REF \\
\hline \multicolumn{5}{|l|}{$\begin{array}{l}\text { Parental rule about which kinds of } \\
\text { food child can eat }(\boldsymbol{P}=\mathbf{. 0 0 3 9})\end{array}$} \\
\hline Yes & 5142 & 76.77 & $34.74(32.98-36.51)$ & $0.77(0.64-0.92)$ \\
\hline No & 1627 & 23.23 & $40.94(37.12-44.76)$ & REF \\
\hline \multicolumn{5}{|l|}{ Current smoking $(P=\mathbf{~ 0 0 3 3})$} \\
\hline Yes & 1303 & 19.56 & $41.43(37.36-45.49)$ & $1.32(1.10-1.60)$ \\
\hline No & 5462 & 80.44 & $34.89(33.14-36.64)$ & REF \\
\hline \multicolumn{5}{|l|}{$\begin{array}{l}\text { Amount of soda consumed by child } \\
\qquad(\boldsymbol{P}=\mathbf{. 0 3 4})\end{array}$} \\
\hline More than 7 per week & 1839 & 26.99 & $39.23(36.21-42.26)$ & $1.03(0.87-1.20)$ \\
\hline Less than 6 time per week & 3019 & 44.08 & $35.12(32.97-37.28)$ & $1.22(1.03-1.45)$ \\
\hline Never & 1903 & 28.93 & $34.56(31.54-37.58)$ & REF \\
\hline Mother's hours work/week $(P=.48)$ & & & & 0.4827 \\
\hline 35 hours or more per week & 2971 & 42.93 & $37.55(35.20-39.90)$ & $1.13(0.95-1.35)$ \\
\hline Less than 35 hours per week & 1257 & 19.13 & $34.99(31.02-38.96)$ & $1.02(0.83-1.24)$ \\
\hline Looking for work & 358 & 5.68 & $35.72(28.24-43.21)$ & $1.05(0.75-1.64)$ \\
\hline Not in the labor force & 2071 & 32.27 & $34.66(31.89-37.44)$ & REF \\
\hline
\end{tabular}


Table 1. Continued

\begin{tabular}{|c|c|c|c|c|}
\hline Risk Factors & $\mathrm{n}$ & Population \% & $\begin{array}{l}\text { \% Overweight or Obese } \\
\qquad(95 \% \mathrm{CI})\end{array}$ & Odds Ratio (95\% CI) \\
\hline \multicolumn{5}{|l|}{$\begin{array}{l}\text { Parental rule about television } \\
\text { watching }(\boldsymbol{P}=\mathbf{. 0 4 1})\end{array}$} \\
\hline Yes & 6274 & 93.82 & $35.77(34.09-37.45)$ & $0.73(0.55-0.99)$ \\
\hline No & 466 & 6.18 & $43.16(36.18-50.14)$ & REF \\
\hline \multicolumn{5}{|l|}{ Neighborhood safety $(\boldsymbol{P}=\mathbf{. 0 0 0 5})$} \\
\hline Very safe & 4012 & 59.40 & $33.71(31.77-35.66)$ & $0.55(0.33-0.91)$ \\
\hline Fairly safe & 2363 & 34.60 & $38.83(35.83-41.82)$ & $0.68(0.41-1.15)$ \\
\hline Very unsafe & 115 & 4.30 & $45.32(37.07-53.57)$ & $0.89(0.48-1.65)$ \\
\hline Refuse & 93 & 1.70 & $48.16(35.15-61.16)$ & REF \\
\hline Overall population & & & $36.31(34.62-37.79)$ & \\
\hline Risk Factors & & $\begin{array}{l}\text { eight/Obese } \\
5 \% \mathrm{CI}) \\
=2246\end{array}$ & $\begin{array}{c}\text { Nonoverweight/Obese } \\
(95 \% \mathrm{CI}) \\
\mathrm{N}=4572\end{array}$ & $P$ Value \\
\hline \multicolumn{5}{|l|}{ Continuous variables } \\
\hline Birth weight (grams) & 343 & $405.9-3466.1)$ & $3248.4(3224.0-3272.9)$ & $<.0001$ \\
\hline Hours TV watched per weekday & & $.92-2.10)$ & $1.86(1.79-1.93)$ & .0045 \\
\hline Days per week eat as a family & & $.38-5.59)$ & $5.66(5.58-5.74)$ & .046 \\
\hline $\begin{array}{l}\text { Parent days per week exercises } \\
\text { for } 30 \text { minutes }\end{array}$ & & $.61-1.90)$ & $1.94(1.83-2.06)$ & .047 \\
\hline
\end{tabular}

Boldface indicates statistical significance $(P<.05)$.

CI, confidential interval; REF, Reference category for odd ratios.

of children in the sample were overweight or obese (Table 1).

In univariable logistic models, all the variables we tested were significantly and independently associated with children being overweight or obese at kindergarten, except child's sex and number of hours worked by the mother (Table 1). In the multivariable logistic regression analysis, SES, race, birth weight, smoking status, and not eating dinner as a family remained statistically significantly associated with children being overweight or obese (Table 2). Interactions between these variables and SES were not statistically significant, indicating that that SES did not modify the relationship between these variables and childhood obesity (Table 2).

We found a significant association of SES for children who were overweight or obese, compared with healthy-weight children. Children in the lowest quintile of SES were $70 \%$ more likely to be overweight or obese than children in the highest quintile (OR 1.7; 95\% CI, 1.3-2.2) Children who were black, Hispanic, Native American, or other races had a statistically significantly increased risk of being overweight or obese compared with white children. Only Asian children had a nonsignificant odds of being overweight or obese compared with white children. Black or Hispanic children had a $60 \%$ increased odds of being overweight or obese when compared with their white counterparts. $\mathrm{Na}$ tive American children had an almost doubled odds of being overweight or obese compared with white children (Table 2). Elevated birth weight was significantly associated with overweight status in children (OR 1.07; 95\% CI, 1.06-1.08). Every 100-g increase in birth weight was associated with a $7 \%$ increased risk of overweight or obesity (Table 2). Parental smoking was associated with $40 \%$ higher odds of child overweight or obesity, while eating dinner as a family was associated with $4 \%$ lower odds.

\section{Discussion}

We found that race, birth weight, parental smoking, and not having family meals were associated with obesity, but there were no statistically significant interaction terms between SES and any of these variables. This suggests the relationship between these variables and childhood obesity were not modified by SES. This is important because the significant risk factors that are modifiable, birth weight, parental smoking, and not eating meals as a 
Table 2. Multiple Logistic Regression Analysis of a Child Being Obese or Overweight at Kindergarten Entry

\begin{tabular}{|c|c|c|c|}
\hline Variables & $\begin{array}{l}\text { Parameter Estimate } \\
\text { (SE) }\end{array}$ & $\begin{array}{c}\text { Odds Ratio for } \\
\text { Overweight/Obesity (95\% CI) }\end{array}$ & $P$ Value \\
\hline $\begin{array}{l}\text { Socioeconomic status (all compared } \\
\text { to ref }=5 \text { th quintile, highest) }\end{array}$ & & & .0018 \\
\hline 1st (lowest) & $0.5384(0.1360)$ & $1.71(1.31-2.23)$ & \\
\hline 2nd & $0.3049(0.1080)$ & $1.36(1.10-1.68)$ & \\
\hline $3 \mathrm{rd}$ & $0.3222(0.1321)$ & $1.38(1.07-1.79)$ & \\
\hline 4th & $0.3104(0.1286)$ & $1.36(1.06-1.76)$ & \\
\hline Race (reference category = white) & & & $<.0001$ \\
\hline Black & $0.4534(0.1337)$ & $1.57(1.21-2.05)$ & \\
\hline Hispanic & $0.4999(0.1183)$ & $1.65(1.31-2.08)$ & \\
\hline Asian & $0.1199(0.1559)$ & $1.13(0.83-1.53)$ & \\
\hline Native American & $0.6823(0.2667)$ & $1.98(1.17-3.34)$ & \\
\hline $\begin{array}{l}\text { Other (includes more than } 1 \\
\text { race) }\end{array}$ & $0.5558(0.1542)$ & $1.74(1.29-2.36)$ & \\
\hline Birthweight (per $100 \mathrm{~g}$ ) & $0.000684(0.000059)$ & $1.07(1.06-1.08)$ & $<.0001$ \\
\hline Current smoker (yes vs no) & $0.3361(0.0905)$ & $1.40(1.17-1.67)$ & .0002 \\
\hline $\begin{array}{l}\text { Eat dinner as a family (days per } \\
\text { week) }\end{array}$ & $-0.038(0.0189)$ & $0.96(0.93-0.99)$ & .0446 \\
\hline \multicolumn{4}{|l|}{ Interaction Effects* } \\
\hline Race $\times$ SES & & & .4263 \\
\hline Birthweight $\times$ SES & & & .3946 \\
\hline Parental Smoking $\times$ SES & & & .5884 \\
\hline Eating dinner as a family $\times$ SES & & & .8809 \\
\hline
\end{tabular}

CI, confidential interval; SE, standard error; SES, socioeconomic status.

${ }^{*}$ Main effect model included race, birthweight, rarental smoking, and eating dinner as a family and evaluated SES as interaction term.

family, could be areas for health care providers to focus anticipatory guidance. Changing the home environment with these modifiable risk factors could indirectly reduce the child's risk for obesity, although it is important to clarify that our study design supports association, not causation.

Our results confirm previous findings that children's weight status in kindergarten varies with SES. ${ }^{11}$ The largest odds ratio of being overweight was between the first and the fifth quintiles for SES. Although many believe that food security contributes to increased obesity rates in low-SES families ${ }^{27}$, we did not find that self-reported food security was a significant predictor. Other studies of food security in children similarly show an inconsistent correlation with weight status. ${ }^{28-30}$ This may result from the difficulty of defining and measuring food security. Other factors felt to contribute to obesity in low-SES families include different feeding behaviors ${ }^{31,32}$ and disproportionately more psychosocial stressors. ${ }^{33}$

By using the SES composite variable, which includes household income as well as parents' education and occupation, our study demon- strated that a combination of socioeconomic factors contribute to children's early obesogenic environment. Thus, a more comprehensive approach to childhood obesity could include interventions targeting parents not only of different income levels, but also of different education levels and occupations. ${ }^{10} \mathrm{We}$ found higher rates of overweight and obesity in black, Native American, and other children in the fourth and fifth quintiles, compared with white children. Because SES did not significantly modify the relationship between race and childhood obesity, other differences should also be considered when addressing childhood obesity. This study supports an increasing body of evidence that racial differences in childhood obesity are not modified by SES. ${ }^{18}$ The higher prevalence of childhood obesity among racial minorities is likely the result of complex interactions between a multitude of factors.

Racial neighborhood differences are believed to be one contributing factor. Specifically, living in neighborhoods with higher poverty levels, lower educational levels, and a high proportion of black 
residents is associated with increased risk of childhood obesity. ${ }^{34}$ Although our univariate analysis found that neighborhood safety was a risk factor for child overweight and obesity, it was not significantly associated with child weight in the multivariable logistic regression model. Other racial neighborhood differences beyond perceived safety, such as inclusivity of the residential community and availability of outside play equipment and recreation resources, may also contribute.

\section{Limitations}

This study was limited by its use of previously collected data. Although our model included many factors that contribute to childhood obesity, objective data about the child's activity level, calories consumed, or maternal weight were not available. However, our model was consistent with many prior studies on childhood obesity. In addition, we only examined weight at kindergarten entry. Further longitudinal analysis may help determine whether the associations of these factors with increased child weight persist into older childhood.

A particular strength of this study is its large, nationally representative population, which reduces the risk of sampling bias. The large sample also allowed us to detect smaller differences in child overweight due to increased power, increasing the model's sensitivity.

\section{Conclusion}

In this ECLS-B secondary data analysis study, we created a regression model from known parental and child risk factors for childhood obesity. SES, race, birth weight, parental smoking, and not eating dinner as a family were associated with overweight and obesity in kindergarten-aged children. SES did not modify the relationship between these variables and childhood obesity. Child health care providers should consider discussing these behaviors with families when addressing childhood obesity. Public health programs that influence risk factors, such as promoting healthy birth weight, reducing parental smoking, and eating meals together as a family, may help improve family health behaviors and environment and thus reduce the risk of childhood obesity.

To see this article online, please go to: http://jabfm.org/content/ 31/4/514.full.

\section{References}

1. Ogden CL, Carroll MD, Kit BK, Flegal KM. Prevalence of childhood and adult obesity in the United States, 2011-2012. JAMA 2014;311:806-14.

2. Cunningham SA, Kramer MR, Narayan KM. Incidence of childhood obesity in the United States. N Engl J Med 2014;370:403-11.

3. Pei Z, Flexeder C, Fuertes E, et al. Early life risk factors of being overweight at 10 years of age: results of the German birth cohorts GINIplus and LISAplus. Eur J Clin Nutr 2013;67:855-62.

4. Boonpleng W, Park CG, Gallo AM, Corte C, McCreary L, Bergren MD. Ecological influences of early childhood obesity: a multilevel analysis. West J Nurs Res 2013;35:742-59.

5. Trost SG, Kerr LM, Ward DS, Pate RR. Physical activity and determinants of physical activity in obese and non-obese children. Int J Obes Relat Metab Disord 2001;25:822-9.

6. Dennison BA, Erb TA, Jenkins PL. Television viewing and television in bedroom associated with overweight risk among low-income preschool children. Pediatrics 2002;109:1028-35.

7. Gibbs BG, Forste R. Socioeconomic status, infant feeding practices and early childhood obesity. Pediatr Obes 2014;9:135-46.

8. Janjua NZ, Mahmood B, Islam MA, Goldenberg RL. Maternal and early childhood risk factors for overweight and obesity among low-income predominantly black children at age five years: a prospective cohort study. J Obes 2012;2012:457173.

9. Melgar-Quinonez HR, Kaiser LL. Relationship of child-feeding practices to overweight in low-income Mexican-American preschool-aged children. J Am Diet Assoc 2004;104:1110-9.

10. Brophy S, Cooksey R, Gravenor MB, et al. Risk factors for childhood obesity at age 5: analysis of the millennium cohort study. BMC Public Health 2009; 9:467.

11. Singh GK, Kogan MD. Childhood obesity in the United States, 1976-2008: trends and current racial/ ethnic, socioeconomic, and geographic disparities. A 75th anniversary publication. Available from: http:// www.hrsa.gov/healthit/images/mchb_obesity_pub. pdf. Published 2010. Accessed 10 November 2014.

12. Natale RA, Messiah SE, Asfour L, Uhlhorn SB, Delamater A, Arheart KL. Role modeling as an early childhood obesity prevention strategy: effect of parents and teachers on preschool children's healthy lifestyle habits. J Dev Behav Pediatr 2014;35:378-87.

13. Toschke AM, Ruckinger S, Bohler E, Von KR. Adjusted population attributable fractions and preventable potential of risk factors for childhood obesity. Public Health Nutr 2007;10:902-6.

14. Gable S, Chang Y, Krull JL. Television watching and frequency of family meals are predictive of overweight onset and persistence in a national 
sample of school-aged children. J Am Diet Assoc 2007;107:53-61.

15. Biro FM, Wien M. Childhood obesity and adult morbidities. Am J Clin Nutr 2010;91:1499S-1505S.

16. Pan L, Blanck HM, Sherry B, Dalenius K, Grummer-Strawn LM. Trends in the prevalence of extreme obesity among US preschool-aged children living in low-income families, 1998-2010. JAMA 2012;308:2563-5.

17. Childhood obesity facts: childhood obesity among preschoolers is more prevalent among those from lower-income families. Available from: http://www. cdc.gov/obesity/data/childhood.html\#obesity-amongpreschoolers. Published 2014. Accessed 7 March 2016.

18. Kimm SY, Obarzanek E, Barton BA, et al. Race, socioeconomic status, and obesity in 9- to 10-yearold girls: the NHLBI Growth and Health Study. Ann Epidemiol 1996;6:266-75.

19. Okosun IS, Annor FB, Seale JP, Eriksen MP. Abdominal adiposity and family income-to-poverty ratio in American women. Obes Res Clin Pract 2014; 8:e201-e298.

20. Datar A, Chung PJ. Changes in socioeconomic, racial/ethnic, and sex disparities in childhood obesity at school entry in the United States. JAMA Pediatr 2015;169:696-7.

21. Fradkin C, Wallander JL, Elliott MN, Tortolero S, Cuccaro P, Schuster MA. Associations between socioeconomic status and obesity in diverse, young adolescents: variation across race/ethnicity and gender. Health Psychol 2015;34:1-9.

22. Shih M, Dumke KA, Goran MI, Simon PA. The association between community-level economic hardship and childhood obesity prevalence in Los Angeles. Pediatr Obes 2013;8:411-7.

23. Bethel J, Green JL, Nord C, Kalton G, West J. Early childhood longitudinal study, birth cohort (ECLSB): methodology report for the 9-month data collection, 2001-02. In: Volume 2: sampling. NCES 2005-147. U.S. Department of Education, Institute of Education Sciences, National Center for Education Statistics: Washington, DC; 2005.

24. Basics about childhood obesity. 2012. Available from: http://www.cdc.gov/obesity/childhood/basics. html. Published 2012. Accessed 10 November 2014.
25. Office of the President, Office of Management and Budget. Standard occupational classification manual. U.S. Department of Commerce, Technology Administration, National Technical Information Service: Springfield, VA; 2000.

26. Jones-Smith JC, Dieckmann MG, Gottlieb L, Chow J, Fernald LC. Socioeconomic status and trajectory of overweight from birth to mid-childhood: the Early Childhood Longitudinal Study-Birth Cohort. PLoS One 2014;9:e100181.

27. Rose D, Bodor JN. Household food insecurity and overweight status in young school children: results from the Early Childhood Longitudinal Study. Pediatrics 2006;117:464-73.

28. Bhargava A, Jolliffe D, Howard LL. Socio-economic, behavioural and environmental factors predicted body weights and household food insecurity scores in the Early Childhood Longitudinal StudyKindergarten. Br J Nutr 2008;100:438-44.

29. Whitaker RC, Orzol SM. Obesity among US urban preschool children: relationships to race, ethnicity, and socioeconomic status. Arch Pediatr Adolesc Med 2006; $160: 578-84$.

30. Gundersen C, Garasky S, Lohman BJ. Food insecurity is not associated with childhood obesity as assessed using multiple measures of obesity. J Nutr 2009;139:1173-8.

31 Murashima M, Hoerr SL, Hughes SO, Kaplowitz SA. Feeding behaviors of low-income mothers: directive control relates to a lower BMI in children, and a nondirective control relates to a healthier diet in preschoolers. Am J Clin Nutr 2012;95:1031-7.

32. Papaioannou MA, Cross MB, Power TG, et al. Feeding style differences in food parenting practices associated with fruit and vegetable intake in children from low-income families. J Nutr Educ Behav 2013; 45:643-51.

33. Gundersen C, Mahatmya D, Garasky S, Lohman B. Linking psychosocial stressors and childhood obesity. Obes Rev 2011;12:e54-e63.

34. Kimbro RT, Denney JT. Neighborhood context and racial/ethnic differences in young children's obesity: structural barriers to interventions. Soc Sci Med 2013;95:97-105. 